\title{
A dental student's fit test troubles
}

By Amber Ahmed, 4th Year Dental Student at the University of Manchester, UK

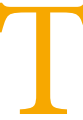

here I was all pepped up ready for my fit test at 11 am on a cold November morning. After listening to my friends' experiences and hearing how quickly their appointments went, I was ready for these ten minutes to be over so I could enjoy the rest of my day.

I was so ready.

After getting this mask I could finally get the privilege of nursing for the fifth years in their fancy AGP sessions. I was deep in thought, contemplating which luxurious coffee my barista would treat me with today. Pumpkin spiced latte or salted mocha frappe? Oh the decisions. Such a difficult choice. Then all of a sudden, I was called in by a familiar voice.

I was greeted by Sarah, a lovely lab technician, who was ready to get the fit test underway. As I walked in, she focused on my face.
'Try again,' she suggested. 'Use a smaller disposable FFP3 mask.'

So off we went again. I was posed in my best yoga position stretching my head side to side continuously. But to my dismay, in the corner of my eye I could see the dial lazily hovering over the red end of the scale.

'Amber, I think we need to try something different', she said.

'Are you sure?' I mumbled.

She reassuringly replied: 'Yes, but don't worry, so many students have had similar problems, so we had to use a different mask.'

'Oh, how many students?' I asked, curiously. As she began unsealing a box, she replied looking down: 'About $5 \%$ of students on ground floor clinic.'

And then she handed me a gas mask. I looked at the thing. I really was ready for the war against COVID-19. Heavy in my hands, I asked: 'Are you sure? Can we not do the test

\section{'Reluctantly, I slipped the gas mask on and began the dreaded test again. One hour in, I was given the green light.'}

'Aha', she cried, 'average disposable FFP3 mask for sure!' It sounded good to me. Being a 5 ' 11" female, I was used to being categorised in the higher end of the scale but happy to be average as I would be deemed normal for once.

Before I knew it, the test was underway.

There I was marching on the spot then turning my head side to side. I was really getting into the swing of things, the rhythm pulsating in my skin then all of a sudden...

'No, no, no', Sarah exclaimed.

I turned to face the screen where I saw four letters shouting at me in red.

'FAIL.'

My earlier eagerness fused out. I was left feeling strange. Whilst Sarah busily began checking the seal around my mask, I was feeling embarrassed for failing this fit test. again with another disposable FFP3 mask?'

'Unfortunately, this is the next option. Have you ever been scuba diving?' she enquired.

$\mathrm{Ha}$, I thought. Me? Scuba diving? She must be joking!

'Nope,' I laughed.

'Well, wearing this mask will feel as if you are scuba diving,' she mused.

Reluctantly, I slipped the gas mask on and began the dreaded test again. One hour in, I was given the green light.

A review carried out by Anaesthesia, the journal of the Association of Anaesthetists, found that the initial pass rates for the fit testing of N95/FFP2/FFP3 masks ranged from $40-90 \%$ and were particularly low in female and in Asian healthcare workers. ${ }^{1}$ They found that initial fit test rates were $90 \%$ in

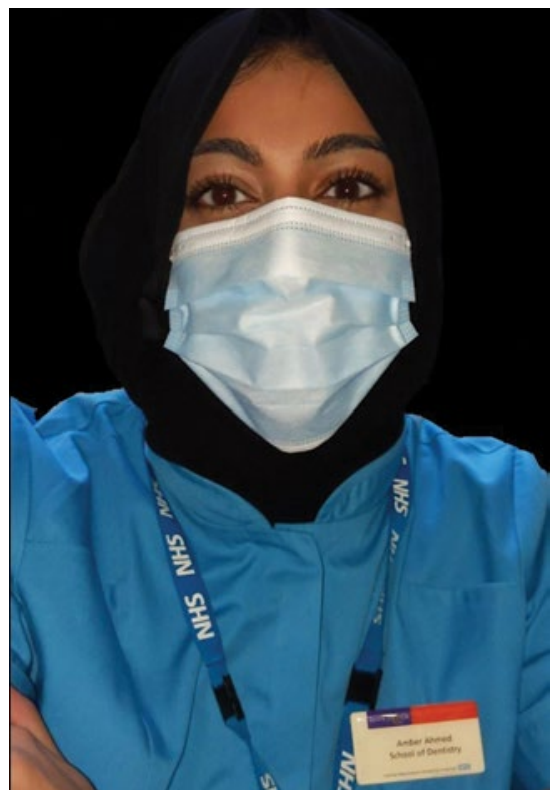

Caucasians in comparison to $84 \%$ in Asians with Asian females' reported mean just $60 \%$. This raises the question: why are the numbers so low in female Asian healthcare workers?

Both the health workers' facial dimensions and shape and size of the mask play crucial roles in preventing leakage ie, best quality of fit. However, when selecting a panel to test the facial dimensions of healthcare workers, a cohort of individuals was chosen where sadly Asian females were underrepresented.

So much more needs to be done to ensure that voices from minority backgrounds reach those at the head of the table. It is vital that people from all walks of life in the NHS are included in the initial tests when PPE are being created.

Even more alarming than these statistics is the realities of doctors in our country. My brother, an A\&E doctor, works day in and day out on a COVID-19 ward with nothing but a surgical mask to protect him. It seems absurd to think that the soldiers on our front line against COVID-19 are placed there with inadequate protection.

In future, if a crisis does arise, we need to ensure that protective gear fits all NHS workers and not just some of us. Not only does it create inequality but also makes those unable to pass the test, question their own identity.

\section{Reference}

1. Regli A, Sommerfield A, von Ungern-Sternberg B S. The role of fit testing N95/FFP2/FFP3 masks: a narrative review. Anaesthesia 2020; https://doi.org/10.1111/ anae.15261. 